\title{
KEMUKJIZATAN AL QUR'AN DARI SEGI KEBAHASAAN DAN KEILMUAN
}

\author{
Vera Fikrotin \\ Universitas KH. A. Wahab Hasbullah/Pendidikan Bahasa Arab/Mahasiswa \\ Email: ferafikro@gmail.com
}

\author{
Aufia Aisa \\ Universitas KH. A. Wahab Hasbullah/ Pendidikan Bahasa Arab/Dosen Pendidikan \\ Bahasa Arab \\ Email: aufiaaisa@unwaha.ac.id
}

\begin{abstract}
Abstrak
Al-Qur'an adalah kalam Alloh yang diturunkan kepada Nabi Muhammad SAW untuk umatnya. Dalam penyampaiannya tentu nya pasti ada perselisihan dan pertentangan mengenai kebenaran al-Qur'an sebagai kalam Ilahi, yang menyebabkan munculnya mu'jizat itu sebagai pelemah musuh pada zaman Nabi mulai dari tantangan dalam pembuatan kitab yang serupa dengan Al-Qur'an. Hingga sampai saat ini banyak orang yang takjub akan kemukjizatan al-Qur'an dari penelitian-penelitian mereka yang mengungkapkan memang al-Qur'an adalah kalam Ilahi yang tidak bisa di rubah maupun ditiru. Banyak para ilmuan yang meneliti al-Qur'an dari segi kebahasaanya dan keilmuannya. Dan bahkan hasilnya pun tetap manakjubkan, memang sangat indah pola kebahasaan dalam al-Qur'an hingga tidak ada yang mampumenandingi dan sangat sempurna dan universal alQur'an dibidang keilmuan.
\end{abstract}

Kata Kunci: Al-Qur'an,Mu'jizat, Kebahasaan, Keilmuan.

\section{A. PENDAHULUAN}

Perkembangan segala ilmu pengetahuan yang melesat cepat terkadang memutuskan bahkan menjauhkan generasi terkini dari fakta-fakta spiritual. Pada realitanya al-Qur'an sebagai kitab pedoman utama Muslim yang merupakan one stop solution untuk segala permasalahan umat manusia. AlQur'an memiliki kemampuan mempertahankan originalnya hingga akhir zaman. Karena Alloh sudah berfirman bahwa Alloh sendirilah yang akan menjaga kesucian al-Qur'an sampai akhir masa. 
Keaslian itulah yang membuatnya diakui memiliki beberapa kelebihan karena tanpa ada perubahan redaksional sekalipun ia tetap relevan dan mampu menjadi pedoman umat. ${ }^{51}$ Al-Qur'an mempunyai setidaknya dua fungsi utama, yaitu sebagai ajaran, dan bukti kebenaran kerosulan Muhammad SAW.

Sebagai sumber ajaran, al-Qur'an memberikan berbagai norma keagamaan sebagai petunjuk bagi kehidupan umat manusia untuk mencapai kebahagiaan di dunia dan di akhirat yang merupakan akhir dari perjalanan hidup mereka. Karena sifatnya memberi arah, norma-norma tersebut kemudian dinamai syariah (syari'ah), yang berarti jalan lurus.

Dalam kajian-kajian keagamaan, istilah syari'ah seringkali direduksi sehingga mempunyai konotasi norma-norma hukum belaka. Padahal, syari'ah mencakup berbagai segi ajaran keagamaan seperti aqidah, akhlak, 'amaliyah, maupun yang lain-lainnya. ${ }^{52}$ Kenyataan ini memperlihatkan bahwa norma-norma syari'ah itu disusun langsung oleh Alloh SWT, dan tidak oleh manusia kecuali untuk pemahaman lebih lanjut.

Hal ini menurut Quraish Shihab merupakan langkah yang amat bijak, karena jika diserahkan kepada umat manusia, niscaya norma-norma tersebut tidak akan sempurna, karena pengetahuan manusia amat terbatas terutama dalam soal-soal yang gaib. Tambahan pula, umat manusia pada umunya

${ }^{51}$ Fathurrosyid, S.Th.I, M. Th.I, dkk, “Studi Al-Qur'an”, (Surabaya:Kopertais IV Press, 2015), hlm, 73.

52Farouk Nabhan, "al-Madkhal li al-Tasyri' al-Islami", (Beirut: Dar al-Qalam, 1981), hlm. 13. 


\section{Kemukjizatan Al-Qur'an dari Segi Kebahasaan dan Keilmuan}

egois, sehingga norma-norma tersebutakan disusun sesuai dengan kepentingan dan kemauan mereka sendiri. ${ }^{53}$

Inilah sekilas rahasia dibalik penyusunan norma-norma syari'ah bagi manusia guna mengatur kehidupan mereka di dunia ini. Kemudian, karena mereka tidak bisa berkomunikasi langsung dengan Alloh dalam menyerap informasi-informasi tersebut, Dia menyampaikannya lewat orang yang memiliki kesucian jiwa dan kecerdasan yang luar biasa, sehingga mampu menerima informasi-informasi ghaib yaitu Rosul . Rosul terakhir yang diberi tugas menyampaikan syari'at adalah Muhammad ibn Abdulloh.

Semua ajaran yang diterima Nabi Muhammad dari Alloh yang dituangkan dalam satu mushaf kitab suci al-Qur'an. Di samping sebagai sumber ajaran, al-Qur'an juga disampaikan Tuhan untuk menjadi bukti kebenaran kerasulan Nabi Muhammad, terutama bagi mereka yang menentang dakwah-dakwahnya. Bukti-bukti kebenaran tersebut dalam kajian ilmu-ilmu al-Qur'an disebut mu'jizat. ${ }^{54}$

Nah, disini akan lebih di jelaskan mengenai mu'jizat al-Qur'an baik dari segi bahasa, pemberitaan, dan keillmuan. Dalam menyikapi kemukjizatan al-Qur'an pastinya banyak perbedaan pendapat dalam menyikapinya. Mulai dari apa fungsi dari mukjizat itu bagi kerosulan Nabi Muhammad pada zaman dahulu maupun zaman sekarang?. Lalu apakah mu'jizat al-Quran akan berakhir saat Nabi muhammad SAW wafat??

\footnotetext{
${ }^{53}$ H. M. Quraish Shihab, "Membumikan al-Qur'an", (Bandung: Mizan, 1992), hlm.28.

${ }^{54}$ Prof. Dr. Quraish Shihab, dkk, "Sejarah \& 'Ulum Al-Qur'an", (Jakarta:Pustaka Firdaus, 2013), hlm.104-105.
} 
Sebenarnya, mu'jizat al-Qur'an membuktikan bahwa al-Qur'an ini benar-benar kitab ilahi. Dari penjelasan di atas, al-Qur'an perlu mendapat perhatian khusus pada pembahasan I'jaznya. Karena pada titik tersebutlah alQur'an menjadi pembeda antara dirinya dan kitab-kitab yang lain.

\section{B. PEMBAHASAN}

1. Makna Kemukjizatan al-Qur'an dan Fungsinya bagi kerasulan Nabi

\section{Muhammad SAW}

Kata mu'jizat sudah menjadi bagian dari khazanah bahasa Indonesia. Sedangkan menurut bahasa Arab sendiri, di gunakan istilah I'jaz al-Qur'an, atau mu'jizat al-Qur'an. Menurut bahasa Mu'jizat berasal dari masdar مُعْجَزَّة artinya adalah melemahkan. Yang mempunyai makna pengokohan al-Qur'an sebagai sesuatu yang mampu melemahkan berbagai tantangan untuk penciptaan karya sejenis. ${ }^{55}$

Dengan demikian, al-Qur'an sebagai mu'jizat bermakna bahwa alQur'an merupakan sesuatu yang mampu melemahkan tantangan menciptakan karya serupa dengannya. Dalam kaitan dengan fungsi kerasulan serta kenabian kenabian Nabi Muhammad terhadap umatnya, kemu'jizatan al-Qur'an tersebut berarti memperlihatkan kebenaran kerosulan dan fungsi kenabiannya serta kitab suci yang dibawanya.

Selain itu, untuk memperlihatkan kekeliruan bangsa Arab yang menentangnya, karena tantangan-tantangan yang dilontarkan Alloh dalam al-Qur'an tidak dapat mereka layani.

${ }^{55} \mathrm{Ibid}, \mathrm{hlm} .76$. 


\section{Kemukjizatan Al-Qur'an dari Segi Kebahasaan dan Keilmuan}

Berdasar pada kisah-kisah yang diangkat al-Qur'an. Al-suyuti membagi mu'jizat para Nabi pada dua kelompok besar, yaitu mu'jizat hisiyah (sesuatu yang dapat ditangkap pancra indra), dan mu'jizat aqliyah (sesuatu yang hanya dapat di tangkap nalar manusia). Mu'jizat hisiyah di tujukan oleh Nabi yang berhadapan dengan umat terdahulu sedangkan mu'jizat 'aqliyah ditujukan untuk Nabi Muhammad SAW. ${ }^{56}$ Lalu Apakah kemu'jizatan alQur'an akan berakhir pada saat wafatnya Nabi Muhammad???

Perlu diketahui, al-Qur'an memiliki sifat berupa tantangan daya nalar, maka kemu'jizatannya tidak berakhir dengan wafatnya Nabi Muhammad. Al-Qur'an tetap mampu menandingi siapa saja yang ingin mencoba menandinginya, termasuk generasi manusia setelah Rosul, dan bahkan umat manusia hari ini, hari esok, dan terus sampai hari akhir.

Mengenai fungsi mu'jizat bagi kerosulan Nabi Muhammad, selain dapat melemahkan para penentang kerosulannya, juga memperlihatkan kebenaran kerosulan Beliau. Al-Qur'an digunakan Nabi untuk menantang orang-orang Arab, tetapi mereka tidak sanggup menghadapinya. Padahal mereka sedemikian tinggi tingkat fasahah dan balagah-nya. Hal ini tidak lain karena al-Qur'an adalah mu'jizat.

Rosululloh telah meminta orang Arab menandingi Qur'an dalam tiga tahapan:

1. Menantang mereka dengan seluruh Qur'an dalam uslub umum yang meliputi orang arab sendiri dan orang lain, manusia dan jin, dengan

56Prof. Dr. Quraish Shihab, dkk, “Sejarah E 'Ulum Al-Qur'an”, (Jakarta:Pustaka Firdaus, 2013), hlm.106. 
tantangan yang mengalahkan kemampuan mereka secara padu melalui firman-Nya:

“katakanlah:sesungguhnya jika manusia dan jin berkumpul untuk membuat yang serupa Qur'an ini, niscaya mereka tidak akan dapat membuat yang serupa dengannya, sekalipun sebagian mereka menjadi pembantu bagi sebagian yang lain." (al-Isra' /17:88)

2. Menantang mereka dengan sepuluh surah saja dari Qur'an, dalam firmanNya:

“Ataukah mereka mengatakan: "Muhammad telah membuat-buat Qur-an itu." Katakanlah: “(Jika demikian), maka datanglah sepuluh surat yang dibuat-buat yang menyamainya, dan panggilah orang-orang yang kamu sanggup (memangginya) selain Alloh, jika kamu memang orang-orang yang benar." Jika mereka (yang kamu seru itu) tidak menerima seruanmu itu, ketahuilah, sesungguhnya Qur'an itu diturunkan dengan ilmu Alloh." (Hud/11:13-14)

3. Menantang mereka dengan satu surah saja dari al-Qur'an, dalam firmanNya:

"Atau patutkah mereka mengatakan, "Muhammad membuat-buatnya. Katakanlah: "(Kalau benar yang kamu katakan itu), cobalah datangkan sebuah surah seumpamanya."(Yunus/10:38). Tantangan ini diulang lagi dalam firman-Nya: 


\section{Kemukjizatan Al-Qur'an dari Segi Kebahasaan dan Keilmuan}

“Dan jika kamu (tetap) dalam keadaan ragu tentang Qur'an yang Kami wahyukan kepada hamba Kami (Muhammad), maka buatlah satu surah saja yang semisal al-Qur'an....". (al-Baqoroh/2:23) ${ }^{57}$

Dua ayat terakhir sekilas tampak sama. Namun jika diperhatikan secara seksama, ayat 38 surah Yunus dikemukakan Alloh tanpa min (bisuratin mitslihi), sedang ayat 23 surah al-Baqoroh menggunakan min (bisuratin min mitslihi) yang bermakna sebagian. Sebab itu pemaknaan terhadap ayat 38 surah Yunus dan ayat 23 surah al-Baqoroh berbeda.

Dan bila dihubungkan dengan berbagai tantangan al-Qur'an terhadap orang-orang kafir, semua ayat tersebut merupakan urutan hirarkis dari tantangan terbesar sampai terkecil yaitu dari tantangan untuk menyusun karya sebesar al-Qur'an sampai hanya beberapa ayat saja dari satu surah yang menyerupai al-Qur'an.

Semua tantangan itu tak mampu dilayani kaum kafir Quraisy, kendati mereka adalah orang-orang yang memiliki kemampuan bahasa yang baik. Ketidakmampuann masyarakat Arab Quraisy memenuhi tantangan balik alQur'an semakin memperkuat kemu'jizatan al-Qur'an. ${ }^{58}$

\section{Kemu'jizatan Al-Qur'an dari segi Kebahasaan}

Abdu al-Razak Naufal ketika meneliti al-Qur'an menemukan keseimbangan-keseimbangan dalam bilangan kata yang dipergunakan alQur'an. Sementara Rasyad Khalifah menemukan konsistensi pemekaian jumlah huruf pembuka surah dalam surah yang bersangkutan. Sedang al-

\footnotetext{
57Manna Khalil al-Qattan, "Studi Al-Qur'an", (Bogor:Pustaka Litera AntarNusa, 2013), hlm. 372. 58Prof. Dr. Quraish Shihab, dkk, "Sejarah \& 'Ulum Al-Qur'an", (Jakarta:Pustaka Firdaus, 2013), hlm.110-111.
} 


\section{Vera Fikrotin dan Aufia Aisa}

Rumani, al-Baqilani, dan Rasyid Ridho melihat sudut keindahan bahasa alQur'an yaang jauh melebihi keindahan sastra Arab.

Di sini ada beberapa keseimbangan dalam al-Qur'an yaitu:

1. Keseimbangan dalam pemakaian kata

Abdul al-Razaq Naufal, menemukan setidaknya lima bentuk keseimbangan kosa kata dalam al-Qur'an, yaitu keseimbangan antara jumlah kata dengan antonimnya, keseimbangan jumlah kata dengan sinonimnya, keseimbangan jumlah kata dengan yang menunjuk akibatnya, keseimbangan jumlah kata dengan penyebabnya, dan keseimbangan-keseimbangan khusus.

a. Keseimbangan jumlah kata dengan antonimnya.

- Al-hayy (hidup) dan al-mawl (mati) masing-masing sebanyak 145 kali;

- An-naf (manfaat) dan al-madharah (madharat), masing-masing sebanyak 50 kali;

- Al-har (panas) dan al-bard (dingin), masing-masing sebanyak 4 kali;

- Ash-shalihat (kebajikan) dan al-sayyi'at (keburukan) masing-masing sebanyak 167 kali;

- Al-rabh (cemas/takut) dan raghbah (harap/ingin) masing-masing sebanyak 8 kali.

b. Keseimbangan jumlah kata dengan sinonimnya.

- Al-harst dan al-zira'ah (membajak/bertani), masing-masing sebanyak 14 kali;

- Al-ushb dan al-dhurur (membanggakan diri/angkuh), masing-masing sebanyak 27 kali; 


\section{Kemukjizatan Al-Qur'an dari Segi Kebahasaan dan Keilmuan}

- Al-dhalim dan mawta (orang sesat/mati jiwanya) masing-masing sebanyak 17 kali;

- Al-Qur'an, al-wahy dan al-islam (al-Qur'an, wahyu dan Islam) masingmasing sebanyak 70 kali;

- Al-aql dan al-nur (akal dan cahaya), masing-masing sebanyak 49 kali;

- Al-jahr dan al-'alaniyah (nyata), masing-masing sebanyak 16 kali.

c. Keseimbangan jumlah antara suatu kata dengan kata lain yang menunjuk pada akibatnya.

- Al-infaq (infak) dengan al-ridho (kerrelaan), masing-masing sebanyak 73 kali;

- Al-bukhl (kekikiran) dan al-khasarah (penyesalan), masing-masing sebanyak 12 kali;

- Al-kafirun (orang-orang kafir) dengan al-nar/al-ahraq (nerraka/pembakaran), masing-masing sebanyak 154 kali;

- Al-zakah (zakat/penyucian) dengan barakah (kebajikan), masing-masing sebanyak 32 kali;

- Al-fasyah (kekejian) dengan al-ghadab (murka), masing-masing sebanyak 26 kali.

d. Keseimbangan antara jumlah kata dengan kata penyebabnya.

- Al-isyraf (pemborosan) dengan al-sur'ah (ketergesa-gesaan), masingmasing sebanyak 23 kali;

- Al-maw 'izhah (nasihat/petuah) dengan al-lisan (lidah), masing-masing sebanyak 25 kali; 


\section{Vera Fikrotin dan Aufia Aisa}

- Al-isra (tawanan) dengan al-harb (perang), masing-masing sebanyak 6 kali;

- As-salam (kedamaian) dengan al-thayyibah (kebajikan), masing-masing sebanyak 60 kali.

e. Selain keseimbangan-keseimbangan di atas, terdapat keseimbangankeseimbangan lain yang bersifat khusus, yaitu:

- Kata yawm (hari) dalam bentuk tunggal ada sebanyak 365, sesuai dengan jumlah hari dalam setahun. Sedangkan kata ayyam (hari dalam bentuk jamak), atau yawmayni (bentuk mutsanna), jumlah pemakaiannya hanya 30, sama dengan jumlah hari dalam sebulan. Di sisi lain, kata yang berarti "bulan" (syahr) hanya terdapat sebanyak 12 kali, sama dengan jumlah bulan dalam setahun.

- Kata-kata yang menunjuk pada utusan Tuhan, yakni rasul, nabiy, basyir, nadzir, keseluruhannya berjumlah 518. Jumlah ini seimbang dengan jumlah penyebutan nama-nama nabi-rasul pembawa berita ajaran keagamaan, yakni sebanyak 518.

2. Konsistensi pemakaian huruf yang menjadi pembuka surah

Hasil penelitian Rasyad Khalifah memperlihatkan keajaiban al-Qur'an sekaligus memperlihatkan otentitasnya, yaitu konsitensi pemakaian huruf yang digunakan sebagai pembuka surah. Dalam surah-surah yang dimulai dengan huruf, jumlah huruf dalam surah itu selalu habis dibagi 19, yang mmerupakan jumlah huruf dalam basmalah. Bahkan semua kata dalam alQur'an yang terrhimpun dalm basmalah juga habis bila di bagi dengan 19 . 


\section{Kemukjizatan Al-Qur'an dari Segi Kebahasaan dan Keilmuan}

Sebagai contoh, huruf qaf yang merupakan pembuka surat ke-50, ditemukan terulang sebanyak 57 kali, yakni 3 x 19. Huruf min yang merupakan pembuka surah al-Qalam terulang sebanyak 133 kali, yakni 7 x 19, huruf $y a^{\prime}$ dan sin pembuka surah yaasin ditemukan terulang sebanyak 285 kali, yakni 15 x 19. Demikian pula dengan huruf-huruf yang dipakai sebagai pembuka pada surah-surah lain.

3. Keindahan susunan kata dan pola-pola kalimatnya

Syeikh Fakhruddin al-Razi, penulis tafsir al-Qur'an berjudul mafatih alGhaib, menyatakan bahwa kefasihan bahasa, keindahan susunan kata, dan pola-pola kalimat al-Qur'an amat luar biasa hingga sulit digambarkan keindahannya.

Sementara itu Qadhi Abu Bakar dalam 'Ijaz al-Qur'an menyatakan bahwa memahami kemu'jizatan al-Qur'an dari sisi keindahan kebahasaanya jika dibandingkan dengan syair dan sastra Arab, amat sukar ditandingi.

Abu Hasan Hazim al-Quthajani menyatakan bahwa keluarbiasaan alQur'an antara lain terlihat dalam konsistensi, kefasihan bahasanya, dan keindahan susunan kalimatnya. Bahkan al-Qur'an amat sempurna dilihat dari semua segi, sehingga tidak mungkin menentukan tingkatan keindahan susunannya itu karena tidak ada alat mengukurnya.

Bundar ibn Husein al-Farisi, seorang ilmuwan dan sastrawan besar dari Persia menyatakan bahwa tingkat kefasihan dan keindahan bahasa al-Qur'an berada diluar jangkauan kemampuan manusia. Kalau mereka mencoba, bisabisa malah sesat. 
Walaupun begitu, bukan mustahil bagi manusia mempelajari dan mendalami sisi-sisi kebahasaan al-Qur'an. Mulai dari 'Ijaz, tasybih, majaz, dan istira'ah. 'Ijaz merupakan penyederhanaan komposisi kalimat tanpa mengurangi arti. Ini merupakan kekhasan kalimat-kalimat yang terdapat dalam al-Qur'an, yakni ringkas-ringkas tetapi bermakna luas.

Sedangkan tasybih, yang dalam ilmu balaghah biasa diartikan sebagai ungkapan yang memperlihatkan bahwa sesuatu itu sama dengan sesuatu yang lain dalam satu atau beberapa sisi atau sifat. Yang digunakan sebagai upaya mendekatkan penjelasan ajaran-ajarannya melalui ilustrasi yang mampu ditangkap indra atau akal manusia.

Kemudian majaz dan isti'arah, dalam ilmu Balaghah, majaz antara lain terbagi dua, yaitu majaz aqli dan majaz lughawi. Dalam penggunaan majaz dalam al-Qur'an banyak perbedaan pendapat diantaranya Daud al-Zahiri, Ibnu al-Qash (dari Syafi'iyah) dan Ibnu Khuwainy (dari Malikiyah) menolak adanya majaz dalam al-Qur'an, karena majaz itu memperlihatkan kebohongan-kebohongan redaksional, padahal al-Qur'an tidak mungkin berdusta.

Tetapi, orang-orang yang mendalami keindahan bahasa dan susunan redaksi al-Qur'an berpandangan bahwa sanggahan di atas kurang tepat. Justru kalau majaz itu di kikis dari al-Qur'an, kitab suci ini sedikit banyak akan kehilangan keindahan pola-pola komposisi kalimatnya. ${ }^{59}$

59Prof. Dr. Quraish Shihab, dkk, "Sejarah \& 'Ulum Al-Qur'an”, (Jakarta:Pustaka Firdaus, 2013), hlm.114-122. 


\section{Kemukjizatan Al-Qur'an dari Segi Kebahasaan dan Keilmuan}

Jadi, dalam segi kebahasaannya di bagian keindahan bahasa al-Qur'an banyak sekali perbedaan pandangan. Dari sini bisa diambil kesimpulan bahwa perbedaan ini menjadi kelebihan tersendiri bagi al-Qur'an karena memang al-Qur'an merupakan kalam Alloh yang benar-benar indah susunannya.

3. Kemu'jizatan Al-Qur'an dari segi Ilmiah

Qur'an adalah kitab akidah dan hidayah. Ia menyeru hati nurani untuk menghidupkan di dalamnya faktor-faktor perkembangan dan kemajuan serta dorongan kebaikan dan keutamaan.

Kemu'jizatan ilmiah Qur'an bukanlah terletak pada pencakupannya akan teori-teori ilmiah yang selalu baru dan berubah serta merupakan hasil usaha manusia dalam penelitian dan pengamatan. Tetapi ia terletak pada dorongannya untuk berpikir dan menggunakan akal. Qur'an mendorong manusia agar memperhatikan dan memikirkan alam.

Ia mendorong kaum Muslimin agar memikirkan makhluk-makhluk Alloh yang ada di langit dan di bumi:

"Sesungguhnya dalam penciptaan langit dan bumi, dan silih bergantinya malam dan siang terdapat tanda-tanda bagi orang-orang yang berakal, yaitu mereka yang mengingat Alloh sambil berdiri atau duduk atau dalam keadaan berbaring dan mereka memikirkan tentang penciptaan langit dan bumi (seraya berkata): Ya Tuhan kami, tiadalah Engkau menciptakan ini dengan sia-sia. Mahasuci Engkau, maka peliharalah kami dari siksa neraka." 
Qur'an mendorong umat Islam agar memikirkan dirinya sendiri, bumi yang di tempatinya dan alam yang mengitarinya:

“Dan mengapakah mereka tidak memikirkan tentang kejadian diri mereka?? Alloh tidak menjadikan langit dan bumi dan apa yang ada di antara keduanya melainkan dengan tujuan yang benar dan waktu yang ditentukan." (ar-Rum/30:8)60

Menurut Ahmad Baiquni, 61 al-Qur'an memberi isyarat bagaimana proses awal alam ini diciptakan. Isyarat itu terlihat antara lain dalam surah al-Anbiya' / 21:30:

“Dan apakah orang-orang kafir tidak mengetahui bahwa langit dan bumi itu keduanya dahulu adalah sesuatu yang padu, kemudian kami pisahkan antara keduanya. Dan dari air kami jadikan segala sesuatu yang hidup, maka mengapakah mereka tiada juga beriman."

Selain seruan untuk orang kafir di ayat ini, Alloh memperlihatkan awal kejadian alam yang menurut informasi al-Qur'an, langit dan bumi pada awalnya satu, kemudian dipecah oleh-Nya sehingga terpisah-pisah. Apa yang dimaksud langit, dan apa pula yang dimaksud bumi, dan bagaimana proses pemisahan tersebut?? Iinilah beberapa pertanyaan yang dapat dikembangkan dari ayat di atas, yang memberi isyarat untuk berpiikir kritis terhadap alam semesta.

${ }^{60}$ Manna Khalil al-Qattan, "Studi Al-Qur'an", (Bogor:Pustaka Litera AntarNusa, 2013), hlm. 386-387.

${ }^{61}$ Ahmad Baiquni, "Islam dan Ilmu Pengetahuan Modern", (Bandung:Pustaka, 1983), hlm. 17-25. 


\section{Kemukjizatan Al-Qur'an dari Segi Kebahasaan dan Keilmuan}

Itu merupakan satu contoh ayat yang menunjukan kemmukjizatan alQu'an dari segi ilmiah. Kemudian di teliti dan memang benar pernyataan yang ada dalam al-Qur'an, dan berikut hasil penelitiannya:

Kata-kata al-sama'(langit) dalam bahasa Arab berarti sesuatu yang berada di atas. Sedang yang dimaksud dengan ardh(bumi), berarti sesuatu yang ada di bawah. Kalau di tafsirkan dalam bahasa ilmu pengetahuan, langit itu tiada lain adalah gugusan bintang-bintang yang berada di luar planet bumi, sedang bumi adalah planet tempat tinggal manusia.

Persoalan gugusan bintang-bintang dengan planet bumi bersatu dalam ayat ini menurut Baiquni bisa terjawab kalau penyatuan terrsebut pada gumpalan hidogren dalam konsentrasi yang amat padat. Sedangkan pemecahan bumi dan langit adalah peristiwa ledakan dahsyat akibat suhu amat panas yang muncul karena gesekan-gesekan atas atom hidogren yang memadat tersebut.

Kemudian dalam analisis laboratorium fisika, kejadian alam berawal dari kondensasi hidogren yang menimbulkan panas yang sangat tinggi, lalu terjadi ledakan besar yang membuat hamparan galaksi-galaksi, yang kemudian memadat karena suhu dingin.

Salah satu dari galaksi-galaksi tersebut adalah galaksi Bima sakti yang memancarkan sinar(matahari) ke planet bumi, serta memberi kehidupan untuk berbagai jenis makhluk di planet bumi termasuk manusia. Kemudian, Alloh juga mengungkapkan bahwa alam ini terus bergerak (expanding universe), sebagaimana dinyatakan dalam surah al-Dzariyat/51:47: 
“Dan langit itu Kami bangun dengan kekuasaan (Kami), dan Kami benar-benar meluaskannya."

Pernyataan ini mengisyaratkan bahwa keseimbangan posisi galaksigalaksi adalah karena tarik-menarik antara satu benda angkasa dengan yang lainnya. ${ }^{62}$

Sebenarnya masih banyak bukti-bukti kemukjizatan al-Qur'an dalam keilmuan. Bukan ilmu alam saja, tapi al-Qur'an bersifat universal. Bisa meliputi ilmu kesehatan atau kedokteran, ilmu agama, fisika, biologi, ilmu petanian, hidrologi, demografi (kependudukan), psikologi, sosiologi, antropologi, dan masih banyak lagi ilmu yang sudah di bahas di dalam alQur'an.

Padahal al-Qur'an adalah kitab yang sudah ribuan tahun yang lalu diturunkan, tapi sudah mampu menjelaskan ilmu dengan pasti dan jelas. Dan ini merupakan bukti kemu'jizatan al-Qur'an dibidang keilmuan. Dan memang al-Qur'an adalah kitab yang diturunkan Alloh Tuhan semesta alam yang meiliki kekuasaan dan ilmu pengetahuan yang sangat luas.

\section{KESIMPULAN}

1. Al-Qur'an merupakan benar-benar kalam Alloh yang diturunkan kepada Nabi Muhammad SAW.

2. Kemu'jizatan yang di miliki al-Qur'ann semata- mata untuk bukti kerosulan Nabi muhammad SAW baik dari segi kebahasaannya dan keilmuannya.

62Prof. Dr. Quraish Shihab, dkk, “Sejarah \& 'Ulum Al-Qur'an”, (Jakarta:Pustaka Firdaus, 2013), hlm.130-131. 
3. Al-Qur'an akan tetap terjaga kemurniannya hingga akhir zaman.

\section{DAFTAR PUSTAKA}

Al-Qattan, Manna Khalil."Studi Al-Qur'an”, (Bogor:Pustaka Litera AntarNusa, 2013). Baiquni, Ahmad. "Islam dan Ilmu Pengetahuan Modern", (Bandung:Pustaka, 1983).

Fathurrosyid, S.Th.I, M. Th.I, dkk, "Studi Al-Qur'an", (Surabaya:Kopertais IV Press, 2015).

Nabhan, Farouk. "al-Madkhal li al-Tasyri' al-Islami”, (Beirut: Dar al-Qalam, 1981).

Shihab, H. M. Quraish."Membumikan al-Qur'an", (Bandung: Mizan, 1992).

Shihab, Prof. Dr. Quraish. dkk, "Sejarah E 'Ulum Al-Qur'an”, (Jakarta:Pustaka Firdaus, 2013). 
Vera Fikrotin dan Aufia Aisa 